Technological diversification, coherence and performance of firms

Bart Leten, René Belderbos and Bart Van Looy

DEPARTMENT OF MANAGERIAL ECONOMICS, STRATEGY AND INNOVATION (MSI) 


\title{
Technological Diversification, Coherence and Performance of Firms
}

\author{
Bart Leten \\ Katholieke Universiteit Leuven \\ Rene Belderbos \\ Katholieke Universiteit Leuven and Technische Universiteit Eindhoven \\ Bart Van Looy \\ Katholieke Universiteit Leuven
}

Corresponding Author:

Bart Leten

Department of Managerial Economics, Strategy and Innovation

Faculty of Economics and Applied Economics

Katholieke Universiteit Leuven

Hogenheuvelcollege

Naamsestraat 69

B-3000 Leuven

Belgium

Phone: +32 16326916

Fax: +3216326732

Email: Bart.Leten@econ.kuleuven.be 


\title{
Technological Diversification, Coherence and Performance of Firms
}

\begin{abstract}
Technological diversification at the level of the firm, i.e. the expansion of a firm's technology base into a wide range of technology fields, is found to be a prevailing phenomenon in all three major industrialized regions: US, Europe and Japan, prompting the term multi-technology corporation. Whereas previous studies have provided insights into the composition of technology portfolios of multi-technology firms, little is known about the link between technological diversification and firms' technological performance. Against a backdrop of the technology and innovation management literature, this article investigates the relationship between technological diversification and technological performance, taking into account the moderating role of technological coherence in firms' technology portfolios. Hereby, technological coherence is defined as the degree to which technologies in a technology portfolio are technologically related. In order to measure the technological coherence of portfolios, a measure of technological relatedness of technology fields is constructed based on patent citation patterns found in 450,000 EPO patent grants. Two hypotheses are presented in this article: (1) Technological diversification has an inverted U-shaped relationship with technological performance; and (2) Technological coherence moderates the relationship between technological diversification and technological performance positively. These hypotheses are tested empirically using a panel dataset (1995-2003) on patent portfolios pertaining to $184 \mathrm{US}$, European, and Japanese firms. The firms selected are the largest R\&D actors in five industries: Pharmaceuticals \& Biotechnology, Chemicals, Engineering \& General Machinery, IT Hardware (computers and communication equipment), and Electronics \& Electrical Machinery. Empirical results, obtained by fixed-effects negative binomial regressions, support both hypotheses in this article. Technological diversification has an inverted U-shaped relationship with technological performance. While technological diversification offers opportunities for cross-fertilization and technology fusion, high levels of diversification may yield few marginal benefits as firms risk lacking sufficient levels of scale to benefit from wide-ranging technological capabilities, and firms may encounter high levels of coordination and integration costs. Further, the results show that the net benefits of technological diversification are higher in technologically coherent technology portfolios. If firms build up a technologically coherent diversified portfolio, the presence of sufficient levels of scale is ensured and coordination costs are limited. This article clearly identifies the important role of technological coherence and points out in the discussion session the relevance of future research on interface management practices directed to the realization of the benefits of technological diversification.
\end{abstract}

Keywords: Technology diversification, technology relatedness, innovation, firm performance 


\section{Introduction}

Innovation is not only one of the driving forces behind welfare creation at the level of regions and nations; it has also been acknowledged as crucial to the long-term survival and growth of the firm (e.g. Schumpeter, 1934: Van de Ven, et al. 1989, 1999; Tushman and Anderson, 1997; Baumol, 2002). Hence, firms build up and/or acquire knowledge in different technology fields, resulting in technology portfolios which can vary in terms of technological diversification and technological coherence. Technology portfolios in which knowledge is spread over many technology fields are considered as signaling higher levels of technological diversification. When the different technology fields share a similar underlying knowledge base, a firm's technology portfolio is considered as technologically coherent. While technological coherence is greatest for focused (non-diversified) technology portfolios, it can and does differ widely between firms that have equally diversified technology portfolios. The impact of these varying degrees of coherence on the relationship between technological diversification and technological performance at the firm level has received scant attention to date $^{1}$.

Drawing on insights from the technology and innovation management literature, this article examines the relationship between technological diversification and technological performance, in conjunction with the technological coherence of firms' technology portfolios. The next section provides an overview of the existing literature on technological diversification and coherence, which allows us to advance the two hypotheses of this article. These focus on the curvilinear relationship between technological diversification and technological performance, on the one hand, and the moderating role of technological coherence on this relationship, on the other. Next, the data, indicators and methods used to assess empirically the central constructs of the paper are discussed. In order to measure the technological coherence of portfolios, a measure of technological relatedness of technology fields is constructed based on patent citation patterns found in approximately 450,000 granted patents. The article finishes with a results section and a discussion of the major findings. Directions for future research are also suggested. 


\section{Theory and Hypotheses}

Large firms' technology portfolios tend to be highly diversified, and technological diversification levels exceed diversification levels of product portfolios (Gambardella and Torrisi, 1998; Pavitt et al, 1989; Patel and Pavitt, 1997). Several reasons have been advanced to explain the technological diversity of large firms' technology portfolios. One driving force is the increasing complexity of products and production processes over time (Rycroft and Kash, 1999), making it necessary for companies to invest in a variety of technology fields. This investment remains a necessity, even in the presence of technological outsourcing as effective assimilation of externally acquired technologies requires the presence of 'absorptive capacity' (Cohen and Levinthal, 1989; Granstrand, Patel and Pavitt, 1997) ${ }^{2}$. Second, firms explore and experiment with new technologies to learn about their commercial potential, which is rarely clear immediately after a new scientific or technological breakthrough occurs (Patel and Pavitt, 1997). The widespread practice of pharmaceutical firms, whose core competencies in the past resided in chemistry, to experiment with biochemical and biological technologies can be seen as an example. Third, as advanced by Penrose (1959), firms learn to use their resources (such as R\&D capabilities) more efficiently over time, which leads to the creation of excess resources. Since R\&D capabilities are often specific in nature, high transaction costs are associated with exploiting them in arm's length markets. Hence, firms may use these excess resources to diversify into promising new technologies.

The drivers of technological diversification present themselves partly as industry-specific as demonstrated by Stephan (2002). He finds that pharmaceutical and telecom firms have technology portfolios which are on average considerably less diverse than those of firms within the automotive, electric engineering, chemical or material industries. Yet, considerable variance in technological diversification levels remains among firms within the same sector. This variance reflects the different bets made by management in the face of technological complexity and uncertainty (Nelson and Winter, 1977; Patel and Pavitt, 1997). At the same time, there is a high persistency over time in the composition of firms' technology portfolios which can be related to the nature of the innovation process that takes place within firms. Innovation can be defined as a cumulative process of incremental problem definition and solving activities (Rosenberg 1982). As many problems are firm-specific, a firm's learning experience is distinctive. Due to the distinctiveness and cumulativeness of a firm's learning experience, its technological trajectory can be characterized as unique and path-dependent (Dosi, 1982; Garud and Karnoe, 2002). Consequently, firms' current technology portfolios 
are, at least partly, a reflection of their past problems, interests and capabilities. Fai (2003) and Cantwell (2004) have found that, even over time periods of 100 years, most firms continue to develop competencies in technology fields in which they gained their initial technological competencies.

\section{Hypotheses}

Several potential positive effects of technological diversification on the technological performance of firms can be pointed out. Firms building up knowledge in multiple fields create the potential to cross-fertilize, yielding new inventions and functionalities and/or increased product and process performances (Granstrand, 1998) ${ }^{3}$. Closely related, a broad technology base may enable firms to create completely new products and services resulting from the combination of knowledge from different technology fields (Argyres, 1996; Hargadon, 1997; Kodama, 1992). According to Kodama (1992), the impact of so-called 'technology fusion' innovations has become more and more important over time. The rise of mechatronics, implying a 'fusion' of knowledge in electronic, mechanical and materials technologies, is a case in point ${ }^{4}$. Recent empirical evidence by Nesta and Saviotti (2005) and Garcia-Vega (2006) has confirmed a general positive impact of technological diversification on firms' technological performance ${ }^{5}$.

Technological diversification is, however, not costless. First, it may prevent firms from creating the focus needed to develop sufficiently strong capabilities in any specific technology domain, necessary to realize economies of scale in technology development. Second, firms with a technologically diversified portfolio are likely to bear larger integration, coordination and communication costs (Granstrand, 1998). These additional coordination costs arise in particular when diversifying firms try to combine more mature technologies with novel, emerging technologies that might conflict with the dominant core technologies of the firm. In line with the notion of creative destruction, advanced by Schumpeter in the mid-1930s, several scholars have pointed to the tensions that organizations encounter when organizing exploitation (of mature technologies) and exploration (of emerging technologies) simultaneously. ${ }^{6}$ Such tensions are experienced especially by 'incumbent firms' as they put in place multiple resources and capabilities aimed at exploitation. The very presence of these resources might hamper engaging in activities of a more explorative nature (Leonard-Barton, 1992). Abernathy (1991) argued that it is almost impossible for an organization to be simultaneously creative and productive. In addition, both activities do differ in terms of their 
contribution to the competitive advantage of a firm, depending on the stage a technology and/or industry finds itself in: whereas creativity can be seen as highly relevant during the pre-dominant design - exploration-oriented - phase; productivity dominates during postdominant design - exploitation-oriented - phase (Abernathy and Utterback, 1978; Anderson and Tushman, 1991). Along similar lines, Ghemawat (1991) - adopting a game-theoretic perspective - points to the irreconcilable nature of 'flexibility' and 'commitment'. As long as exploration is a priority, one needs to remain flexible from an organizational point of view. Once committed, i.e. once a firm has adopted a determined exploitation trajectory, flexibility is at odds with the dominant mode of organization required for exploitative purposes. Ghemawat argues that this duality of 'flexibility' versus 'commitment' is extremely difficult to handle and to maintain simultaneously within an organization. More recently, Benner and Tushman (2003) also point to these tensions when discussing the impact of process management activities on exploitation and exploration trajectories.

The above suggests a complex, non-linear relationship between the level of technological diversification and firms' technological performance. While technological diversification offers opportunities for cross-fertilization and technology fusion, higher levels of technological diversification may yield fewer marginal benefits as firms risk lacking sufficient levels of scale to benefit sufficiently from wide-ranging technological diversification. In addition, coordination and integration costs may increase exponentially with higher levels of technological diversification, as more diversified firms are more likely to encounter difficulties in combining mature (exploitative) technologies with explorative trajectories. This leads to the following hypothesis:

Hypothesis 1: Technological diversification has an inverted U-shaped relationship with technological performance.

As outlined above, when implementing technological diversification strategies, firms may encounter situations in which they have to find ways to handle the tensions between exploiting existing technological trajectories and exploring new technologies. Recently, several scholars have advanced the notions of semi- or quasi-structures (Schoonhoven and Jellinek, 1990; Brown and Eisenhardt, 1997) and ambidextrous organizations (Tushman, Anderson and O'Reilly, 1997; Benner and Tushman, 2003, O'Reilly and Tushman, 2004) to handle the opposing requirements. An additional moderator of the organizational and 
managerial complexities encountered - besides organizational design choices - might be found in the level of synergetic potential in a firm's technology portfolio. Diversified firms might be able to outperform focused or less diversified firms when technological relatedness allows such synergies to be enacted (Van Looy, Martens and Debackere, 2005). Stated otherwise, the potential for synergy might be dependent on the technological coherence of a firm's technology portfolio. A technology portfolio is considered technologically coherent when it combines technologies that share a common knowledge base, rely upon common scientific principles or have similar heuristics of search (Breschi, Lissoni and Malerba, 2003). Firms that diversify their technology portfolio in a technologically coherent way may be able to attenuate the potential negative impact of technological diversification: coherence implies the presence of sufficient scale and facilitates coordination and communication (Allen, 1977; Peltz and Andrews, 1967). At the same time, technologically coherent diversification is likely to put firms in a better position to enact the cross-fertilization potential offered by their presence in a variety of technology fields. Therefore, the following is hypothesized:

Hypothesis 2: The higher the degree of technological coherence in a firm's technology portfolio, the greater the positive impact of technological diversification on technological performance.

\section{Data and Methods}

Data

In order to investigate the impact of technological diversification and coherence on firms' technological performance, a panel data set is built up. This data set contains information on patent applications from 184 European, US, and Japanese firms that are active in 5 industries: (1) Engineering \& General Machinery, (2) Pharmaceuticals \& Biotech, (3) Chemicals, (4) IT Hardware (computers and communication equipment), and (5) Electronics \& Electrical Machinery. The firms selected are the top R\&D spenders in their region of origin and industry as indicated by the '2004 EU Industrial R\&D Investment Scoreboard'. The resulting sample contains roughly the same number of firms in each industry for each region of origin (Table 1). The sample firms are observed over 9 years (1995-2003).

\section{INSERT TABLE 1}


Patent application data are used as an indicator of a firm's technological performance and to construct technological diversification and coherence measures. Compared to other technology indicators, the use of patent data has several advantages: (1) they are easily available at the level of the firm (2) they cover fairly long time series and (3) they provide detailed information on the technological content of a firm's innovation activities. Disadvantages of working with patent data include the poor coverage of software innovations (particularly important in the IT sector) and varying patent propensities among industries and, to a lesser extent, firms ${ }^{7}$ (Griliches, 1990). While patent grants are more reliable indicators of innovations, our dataset is constructed based on patent applications. Patent granting decisions in the European Patent Office, our source of patent data, take on average 4 years, making patent grants a poor indicator of recent innovation activities of firms.

Patent data are collected at the consolidated level, i.e. all patents assigned to the parent firm as well as consolidated (majority-owned) subsidiaries of the parent firm are taken into account to assess the technological performance, diversification, and coherence of the sample firms. For this purpose, yearly lists of subsidiaries included in annual reports, yearly 10-K reports filed with the SEC in the US and, for Japanese firms, information on foreign subsidiaries published by Toyo Keizai in the yearly Directories of Japanese Overseas Investments, are used. The consolidation was performed on a yearly basis since the group structures of parent firms may change substantially over time due to acquisitions, mergers, de-mergers, and spin-offs. Constructing 'consolidated' patent portfolios is important since on average 20 percent of the patents in the patent portfolios of parent firms are not applied under the (current) name of the parent firm (Magerman et al, 2005).

The consolidated patent portfolios of parent firms are constructed on the basis of a moving time window of 5 years. Hence, the consolidated patent portfolio of a parent firm in year $i$ consists of all patent applications in the past five years by the entities that were part of the parent firm in year $i$. Such a moving window of five years allows for a reliable measurement of the levels of technological coherence and technological diversification in firm patent portfolios and has been found an appropriate time frame for assessing technological impact in high-tech industries (Vanhaverbeke, Duysters and Beerkens, 2002). 


\section{Dependent variable and Estimation Method}

The dependent variable, PATENT, is the yearly number of firm EPO patent applications over the time period 1995-2003. Since the dependent variable takes only non-negative integer values, a negative binomial panel data fixed effects model is employed. This panel data estimation technique controls for the impact of unobserved firm-specific characteristics on firms' technological performance (characteristics that may correlate with, and bias the effect of the explanatory variables, if not controlled for).

\section{Technological diversification}

All patents contain one or more technology field codes (IPC classification), which are given by the patent examiners of EPO. Each of those 8-digit IPC codes (+- 64000) stands for a particular technical function or application (OECD, 1994). This article uses a technologyoriented classification that assigns each IPC code to one of 30 different technology fields. This classification has been elaborated jointly by Fraunhofer-Gesellschaft-ISI, Institut National de la Propriété Industrielle (INPI) and Observatoire des Sciences and des Techniques (OST) and is reported in Appendix 1. The technology class information of the patents in a firm's patent portfolio is used to derive measures of technological diversification and technological coherence. Technological diversification is defined as the spread of the patent portfolio over technology classes. Let $\mathrm{N}_{\mathrm{i}}$ denote the number of patents in the technology portfolio of a certain firm that are assigned to technology class $i$, such that $\mathrm{N}=\Sigma_{\mathrm{i}} \mathrm{N}_{\mathrm{i}}$. Technological diversification is then defined as:

$$
\mathrm{DIV}=1 /\left(\Sigma_{\mathrm{i}}\left(\mathrm{N}_{\mathrm{i}} / \mathrm{N}\right)^{2}\right)
$$

This definition is a transformation of the so-called Herfindahl index $\left(\Sigma_{\mathrm{i}}\left(\mathrm{N}_{\mathrm{i}} / \mathrm{N}\right)^{2}\right)$. The Herfindahl index measures the degree of concentration of patents among patent classes. It takes the value 1 if firms have patents in a single class only, and approaches zero if patents are evenly dispersed over a large number of technology fields. This variable is a more accurate measurement of technological diversification than a simple count of technologies in a firm's knowledge base, since the latter is very sensitive to accidental discoveries in particular technology fields. The variable DIV transforms the Herfindahl measure into a measure of diversification by taking the inverse. The index is usually termed the 'equal distribution number equivalent' of the Herfindahl index: the value represents the number of technology fields over which patents would have to be equally distributed in order to generate 
the same value of the equal distribution number equivalent. In the case of the abovementioned technology classification, the minimum value is 1 and the theoretical maximum is 30. For example, if a firm has a portfolio of 100 patents, which are equally spread among 10 technology classes, the Herfindahl index is 0.1 and the diversification index DIV is equal to 10. If, however, among the 10 classes, patents are largely concentrated in one or two classes, the level of diversification DIV drops below 10. For instance, if two classes have 30 patents, and the remaining 8 each have 5, the Herfindahl index is 0.2 and the index DIV is 5: the distribution of patents leads to the same DIV index as an equal distribution of the 100 patents over 5 classes.

In order to test for a non-linear relationship between technological diversification and technological performance, both the linear (DIV) and squared (DIV ${ }^{2}$ term of technological diversification are included in the empirical model. As stated in hypothesis 1, a positive sign for DIV and a negative sign for $\mathrm{DIV}^{2}$ are expected.

\section{Technological Coherence}

Technological coherence is defined as the degree to which technologies share the same underlying knowledge base ('technologically-related' technologies). In order to calculate the technological coherence of a firm's patent portfolio, one needs, for each pair of technology classes in a patent portfolio, a measure of the level of technological-relatedness. The most common approach to constructing such a measure is to examine technological information available in patent databases. The approach taken in past research builds on the jointoccurrence of different technology classes as found in patent documents (Engelsman and Van Raan, 1992; Breschi, Lissoni and Malerba, 2003). Two technology classes are considered as technologically-related if they occur frequently together as technology classification codes on the same patents. In this article, a novel approach, which relies on citation patterns in patent documents, is followed. Two technology classes are considered as technologically-related if patents classified in one technology class often cite patents classified in the other technology class (and visa versa). Since the variation among patent citations is much larger than that of the joint-occurrence of technology classification codes, this approach allows for a more finegrained characterization of technological-relatedness. Furthermore, arguably patent citations are a more direct measure of technological-relatedness since the cited patents represent 'prior art' relevant to qualify the claims advanced in the citing patent applications. The 'technological universe' on the basis of which our technological-relatedness measure is 
calculated is the collection of all EPO patent grants up to 2003 applied for between 1990 and 2003 (and granted before June 2005). Most of these 456,340 EPO patent grants (98\%) contain cited patents, which originate mainly from USPTO and EPO ${ }^{8}$. For these citations $(969,471)$ information on technological classes can be extracted and used subsequently to assess technological-relatedness between classes.

A straightforward way to measure the technological-relatedness of two technology classes is to compare the observed numbers of citations between these classes with expected numbers of citations, under the hypothesis of random occurrence of technology classes on cited patents. Let $\mathrm{O}_{\mathrm{ij}}$ be the observed number of cited patents of technology class $\mathrm{j}$ in citing patent grants of technology class $\mathrm{i}$, with $\mathrm{O}_{\mathrm{i}}=\sum_{\mathrm{j}} \mathrm{O}_{\mathrm{ij}}{ }^{9}$. A certain technology class has a higher random probability to be cited if many patents are classified in that technology class. Let $\mathrm{N}_{\mathrm{j}}$ be the total number of patents that are classified in technology class $j$, with $T=\sum_{j} N_{j}$. This gives the following expression for the expected - random - number of cited patents of technology class $\mathrm{j}$ in citing patents of technology class $\mathrm{i}\left(\mathrm{E}_{\mathrm{ij}}\right)$ :

$$
\mathrm{E}_{\mathrm{ij}}=\mathrm{O}_{\mathrm{i}} *\left(\mathrm{~N}_{\mathrm{j}} / \mathrm{T}\right)
$$

A measure of technological-relatedness is then calculated as follows:

$$
\mathrm{R}_{\mathrm{ij}}=\left(\mathrm{O}_{\mathrm{ij}}+\mathrm{O}_{\mathrm{jj}}\right) /\left(\mathrm{E}_{\mathrm{ij}}+\mathrm{E}_{\mathrm{ji}}\right)
$$

This leads to the creation of a 'symmetric' matrix (30x30, with empty diagonal elements) of relatedness measures for each pair of (distinctive) technology classes. The interpretation of $\mathrm{R}_{\mathrm{ij}}$ is straightforward: if $R_{i j}>1$, then technologies $i$ and $j$ are more related than could be expected on the basis of random citation patterns. The technology-relatedness matrix is given in Appendix 2.

The technology-relatedness matrix is used to calculate the technological coherence of a firm's technology portfolio, with the latter defined as the weighted (by means of consolidated patent numbers on the level of the firm) average technological-relatedness of all pairs of technologies in a technology portfolio. In line with the work of Teece et al (1994) on productrelatedness measures, our measure of technological coherence at the level of the firm is calculated in two steps. First, for each technology in a firm's patent portfolio, the weighted 
average relatedness $\left(\mathrm{COH}_{\mathrm{i}}\right)$ of that technology to all other technologies within the firm is calculated:

$$
\mathrm{COH}_{\mathrm{i}}=\left(\sum_{\mathrm{i} \neq \mathrm{j}} \mathrm{R}_{\mathrm{ij}} * \mathrm{P}_{\mathrm{j}}\right) /\left(\sum_{\mathrm{i} \neq \mathrm{j}} \mathrm{P}_{\mathrm{j}}\right)
$$

This measure indicates to which extent technology field $\mathrm{i}$ is related to all other technology fields in a firm's technology portfolio, weighted by the patent counts in each technology field $\left(\mathrm{P}_{\mathrm{j}}\right)$. The overall coherence measure of a firm's technology portfolio is then defined as the weighted average of all the $\mathrm{COH}_{\mathrm{i}}$ measures:

$$
\mathrm{COH}=\left(\sum_{\mathrm{i}} \mathrm{COH}_{\mathrm{i}} * \mathrm{P}_{\mathrm{i}}\right) /\left(\sum_{\mathrm{i}} \mathrm{P}_{\mathrm{i}}\right)
$$

The coherence index $\mathrm{COH}$ is calculated on the 1-year lagged patent portfolio of the firm, which is taken as a five-year moving window of firms' patent applications. Hypothesis 2 predicts that $\mathrm{COH}$ has a positive moderating effect on the impact of DIV on technological performance. Hence, we include the interaction effect of DIV and $\mathrm{COH}$ in our empirical analyses and expect a positive sign. The analysis also includes a main effect of $\mathrm{COH}$, to avoid a bias in the estimates of the interaction term between diversification and coherence (Braumoeller, 2004).

\section{Control variables}

Our empirical model controls for other factors that are likely to impact technological performance. As emphasized already by Pakes and Griliches (1984), changes in R\&D expenditures are likely to result (with small time lags) in subsequent changes in patent numbers ${ }^{10}$. To control for changes in R\&D expenditures, the 1-year lagged R\&D expenditures of the firm (R\&D), measured in constant US dollars (millions) are included. The data on firms' R\&D expenditures are collected from annual financial reports (source: Worldscope, Compustat and annual reports). A second control variable is the size of the lagged patent portfolio of the firm (PORTFOLIO). Firms with a large stock of patent applications are expected to be more effective in producing new patent applications. Finally, the model also includes 8 time dummies to account for time-specific factors affecting the number of patent applications. 


\section{Descriptive Statistics}

Descriptive statistics of the dependent and explanatory variables can be found in Table 2 . The mean numbers of patent applications and lagged R\&D expenditures in our sample amount to 125 and 674 million dollars in respective order. The mean technological diversification measure is 4.56. As one may expect, the patent portfolios exhibit technological coherence: an average value of 1.33 (above 1) for the $\mathrm{COH}$ variable indicates that firms combine technologies that cite each other more frequently than a random citation pattern would suggest.

Table 3 contains the coefficients of correlation between the variables of interest. The patent stock correlates highly with the rate of new patent applications. Technological diversification correlates negatively, but not particularly strong, with the level of technological coherence. As to be expected, the correlation between diversification and its squared term is considerable.

INSERT TABLES 2 and 3

\section{Empirical Results}

The results of the fixed effects negative binomial estimation of the relationship between technological performance (the number of patent applications, PATENT), technological diversification and coherence are presented in Table $4^{11}$. Model 1 includes only the control variables. $R \& D$ and the size of the lagged patent portfolio have the expected positive signs and are significant ${ }^{12}$. The time dummy coefficients indicate a yearly increase in patent applications up to 2002 (the reference year is 1995), followed by a decline in 2003. The decline in 2003 is partly due to the fact that not all patent applications filed in 2003 had been published and recorded in our database at the moment of data retrieval. In addition, the increasing trend to file patents directly under the PCT Treaty - extending the period between application and publication - explains the observed coefficient.

The linear (DIV) and squared $\left(\mathrm{DIV}^{2}\right)$ terms of technological diversification are added in Model 2, showing a positive and significant impact of the linear term and a negative and significant impact of the squared term. These results strongly confirm hypothesis 1: the 
marginal effect of technological diversification is initially positive, but decreases after a certain level of diversification to become negative for highly diversified firms. In Model 3, the interaction term between technological diversification and technological coherence, as well as the main effect of coherence, are added. The coefficient of the interaction term is positive and significant while the coefficient of the main effect is negative but not significant. This supports our hypothesis 2: the higher the level of technological coherence of a firm's technology portfolio, the greater the positive impact of technological diversification on a firm's technological performance. Figure 1 illustrates our findings graphically. The figure depicts the predicted values of Model 3, calculated at the sample mean (average values for controls and fixed effect, year dummy 1999 set to 1), for varying values of DIV and COH. Technological diversification varies between 1 and 20 for three different values of coherence: average coherence ( $\mathrm{COH}$ mean), average coherence minus one standard deviation ( $\mathrm{COH}$ low), and average coherence plus one standard deviation ( $\mathrm{COH}$ high). The figures illustrate that the relationship between technological diversification and performance is inverted U-shaped, while higher levels of technological coherence lead to a greater positive impact of diversification on performance. The optimal level of technological diversification depends on the level of technological coherence. For low coherent firms it is around 9, but this value increases to 13 and 16 for mean coherent and high coherent firms, respectively. While one has to be cautious in interpreting the predicted impacts ${ }^{13}$, Figure 1 shows that the magnitude of the impact of technological coherence on patent applications is substantial. A high-coherent firm active in 4 equally important (in terms of patent numbers) technology fields is predicted to have 60 percent (123 versus 77 ) more patent applications than an equally diversified firm characterized by low levels of coherence. Similarly, diversification conditional on sufficient coherence can have a large impact on patent applications. An average coherent firm active in 4 equally important technology fields increases its yearly number of patent applications by 15 percent $(97.5$ to 115$)$ if it becomes active in a $5^{\text {th }}$ (equally important) technology class.

\section{Conclusion and Discussion}

This article examined the relationship between technological diversification and technological performance of firms in conjunction with the technological coherence of firms' technology portfolios. Based on insights from the technology and innovation management literature, technological diversification is expected to have an inverted U-shaped relationship with technological performance. While technological diversification offers opportunities for cross- 
fertilization and technology fusion, higher levels of technological diversification may yield fewer marginal benefits as firms risk lacking sufficient levels of scale to benefit sufficiently from wide-ranging technological capabilities. In addition, coordination and integration costs may increase exponentially with higher levels of technological diversification, as highly diversified firms are more likely to encounter difficulties in combining mature (exploitative) technologies with explorative trajectories. Second, the level of technological coherence of firms' technology portfolios is expected to moderate the relationship between technological diversification and performance positively. If firms diversify into 'technologically-related' technologies - i.e. technologies that share a common knowledge base rely upon common scientific principles or have similar heuristics of search - the presence of sufficient levels of scale is ensured while, at the same time, coordination costs may be reduced. Hence, technological coherent diversification puts firms in a better position to increase their technological output. Strong empirical support for our hypotheses is found in a fixed effects panel data analysis of the technological performance (as measured by yearly patent applications) of 184 high R\&D spending US, European, and Japanese firms in five high-tech industries.

These findings inform managerial practices with respect to technological diversification in different ways. The study shows that there exist limits with respect to the net benefits of firms' technological diversification, and that too much diversification may negatively impact technological performance. Firms can increase the benefits of diversification and limit the disadvantages by choosing the direction of diversification carefully and extending their activities into technology fields that share a common knowledge base with the firm's existing technology portfolio. So, besides organizational design choices (e.g. O'Reilly and Tushman, 2004), technology characteristics (such as technological-relatedness) should be taken into account when taking strategic decisions on the composition and organization of technology portfolios. The study clearly identifies technological coherence as a promising area for further research. Future research focusing on the adoption of interface management practices directed towards enacting synergies and the precise nature of technological coherence within such processes seems highly relevant. Another avenue for future research relates to analyzing the relationship between technological diversification and firms' financial performance, taking into account the moderating role of technological coherence. The omission of technological 
coherence in previous work (Gambardella and Torrisi, 1998; D’Este, 2005; Giuri, Hagedoorn and Mariani, 2004) may be one factor explaining the mixed results of those studies. 


\section{References}

1) Abernathy, W. (1991). The productivity dilemma. Baltimore: John Hopkins University Press.

2) Abernathy, W. and Utterback, J. (1978). Patterns of industrial innovation. Technology Review 7, 40-47.

3) Allen, T. (1977). Managing the flow of technology. Cambridge (MA): MIT press.

4) Anderson, P. and Tushman, M. (1991). Managing through cycles of technological change. Research-Technology Management. May/June, 26-31.

5) Argyres, N. (1996). Capabilities, technological diversification and divisionalization. Strategic Management Journal 17(5), 395-410.

6) Arundel, A. and Kabla, I. (1998). What percentage of innovations are patented? Empirical estimates from European firms. Research Policy 27, 127-141.

7) Baumol, W. (2002). The free-market innovation machine: Analyzing the growth miracle of capitalism. New Jersey: Princeton University Press, 1-307.

8) Benner, M.J. and Tushman, M.L. (2003). Exploitation, exploration and process management: The productivity dilemma revisited. The Academy of Management Review 28(2), 238-256.

9) Braumoeller, B.F. (2004). Hypothesis testing and multiplicative interaction terms. International Organization 58 (Fall), 807-820.

10) Breschi, S., Lissoni, F. and Malerba, F. (2003). Knowledge-relatedness in firm technological diversification. Research Policy 32, 69-87.

11) Brown, S.L., Eisenhardt, K.M. (1997). The art of continuous change: linking complexity theory and time-paced evolution in relentessly shifting organizations. Administrative Science Quaterly 42(1), 1-34.

12) Cantwell J. (2004). An historical change in the nature of corporate technological diversification. In: The economies and management of technological diversification. Cantwell, J., Garmbardella, A. and Granstrand, O. (Eds). Routledge, 265-296.

13) Cohen, W.M. and Levinthal, D.A. (1990). Absorptive capacity: a new perspective on learning and innovation. Administrative Science Quaterly 35, 128-152.

14) D'Este, P. (2005). How do firms' knowledge bases affect intra-industry heterogeneity? An analysis of Spanish pharmaceutical industry. Research Policy 34(1), 33-45.

15) Dosi, G. (1982). Technological paradigms and technological trajectories. Research Policy, 11 147-162. 
16) Engelsman, E.C. and Van Raan, A.F.J. (1992). A patent-based cartography of technology. Research Policy 23, 1-26.

17) Fai, F. (2003). Corporate technological competence and the evolution of technological diversification. US: Cheltenham, 1-194.

18) Gambardella, A. and Torrisi, S. (1998). Does technological convergence imply convergence in markets? Evidence from the electronics industry. Research Policy 27, 445463.

19) Garcia-Vega, M. (2006). Does technological diversification promote innovation? An empirical analysis for European firms. Research Policy 35, 230-246.

20) Garud, R. and Karnoe, P. (2002). Path Dependency and Creation. LEA Publishers.

21) Ghemawat, P. (1991). Flexibilty and Commitment: The dynamics of strategy. New York: Free Press.

22) Giuri, P., Hagedoorn, J. and Mariani, M. (2004). Technological diversification and strategic alliances. In: The economies and management of technological diversification. Cantwell J., Garmbardella A., Granstrand O. (Eds). Routledge, 116-151.

23) Granstrand, O. (1998). Towards a theory of the technology-based firm. Research Policy $27,465-489$.

24) Granstrand, O., Patel, P. and Pavitt, K. (1997). Multi-technology corporations: why do they have "distributed" rather than "distinctive core" competencies. California Management Review 39, 8-25.

25) Griliches, Z. (1990). Patent statistics as economic indicators - a survey. Journal of Economic Literature 28(4), 1661-1707.

26) Hargadon, A.B. (1997). Technology brokering and innovation in a product development firm. Administrative Science Quaterly 42, 716-749.

27) Kodama, F. (1992). Technology fusion and the new R\&D. Harvard Business Review 70(4), 70-78.

28) Leonard-Barton, D. (1992). Core capabilities and core rigidities: A paradox in managing new product development. Strategic Management Journal 13 (Summer Special Issue), 111125 .

29) Magerman, T., Van Looy, B., DuPlessis, M., Verbeek, A.and Leten, B. (2005). Data Production methods for harmonised patent statistics, Eurostat Report.

30) March, J. (1991). Exploration and exploitation in organizational learning. Organization Science 2(1), 71-87. 
31) Nelson, R. and Winter, S. (1977). In search of useful theory of innovation. Research Policy 6, 36-76.

32) Nesta, L. and Saviotti, P.P. (2005). Coherence of the knowledge base and the firm's innovative performance: Evidence from the US pharmaceutical industry. Journal of industrial economics 53(1), 123-142.

33) OECD (1994). The measurement of scientific and technological activities: Using patent data as science and technology indicators - Patent Manual 1994, OECD, Paris.

34) O'Reilly, C. and Tushman, M.J. (2004). The Ambidextrous Organization. Harvard Business Review April, 74-81.

35) Pakes, A. and Griliches, Z. (1984). Patents and R\&D at the firm level: A first look. In: R\&D, Patents and Productivity. Griliches, Z. (Eds). NBER, 55-72.

36) Patel, P. and Pavitt, K. (1997). The technological competencies of the world's largest firms: complex and path-dependent, but not much variety, Research Policy 26, 141-156.

37) Pavitt, K., Robson, M. and Townsend, J. (1989). Technological accumulation, diversification and organization in UK companies, 1945-183. Management Science 35(1), 8199.

38) Pelz, D.C. and Andrews, F.M. (1966). Scientists in organization: Productive climates for research and development. NY:Wiley.

39) Penrose, E. (1959). The theory of the firm. Oxford Basil Blackwell, 1-272.

40) Prencipe, A. (2004). The changing boundaries of the firm: Empirical evidence from the aircraft engine industry. In: The economies and management of technological diversification. Cantwell, J., Garmbardella, A. and Granstrand, O. (Eds). Routledge, 234-261.

41) Rosenberg, N. (1982). Inside the black box: technologies and economics. Cambridge University Press, 1-304.

42) Rycroft, R.W. and Kash, D.E. (1999). The complexity challenge: Technological innovation for the $21^{\text {st }}$ century. Cassell Academic Publishers.

43) Schoonoven, B. and Jelinek, M. (1990). Dynamic tension in innovative, high technology firms: managing rapid technological change through organizational culture. Reprinted in: Managing Strategic Innovation and Change. Tushman, M.L. and Anderson, P. (Eds). Oxford University Press.

44) Schumpeter, J.A. (1934). Business cycles: a theoretical, historical and statistical analysis of the capitalist process. New York, McGraw-Hill, 1-461. 
45) Stephan, M. (2002). Diversification profiles of multinational corporations: an empirical investigation of geographical diversification, product diversification and technological diversification. Paper prepared for $28^{\text {th }}$ EIBA Conference 2002, Athens, Greece.

46) Suzuki, J. and Kodama, F. (2004). Technological diversity of persistent innovators in Japan: two case studies of large Japanese firms. Research Policy 33, 531-549.

47) Teece, D., Rumelt, R., Dosi, G. and Winter, S. (1994). Understanding corporate coherence. Journal of Economic Behavior and Organization 23, 1-30.

48) Tushman, M., Anderson, P.C. and O'Reilly C. (1997). Technology cycles, innovation streams, and ambidextrous organizations: organizational renewal through innovation streams and strategic change. In: Managing strategic innovation and change: a collection of readings. Tushman, M.L. and Anderson P.C. (Eds). NY: Oxford University Press.

49) Van de Ven, A., Angle, H. and Poole, M.S. (1989). Research on the Management of Innovation: The Minnesota Studies. Harper \& Row Publishers, 1-712.

50) Van de Ven, A., Polley, D., Garud, R. and Venkatraman, S. (1999). The Innovation Journey. Oxford University Press, 1-424.

51) Vanhaverbeke, W., Duysters, G. and Beerkens, B. (2002). Technology capability building through networking strategies within high-tech industries. Academy of Management best paper proceedings, Denver, Colorado: Academy of Management.

52) Van Looy, B., Martens, T. and Debackere, K. (2005). Organizing for Continuous Innovation: On the sustainability of Ambidextrous Organizations. Creativity and Innovation Management Journal 14(3) 208-221. 


\section{TABLES, FIGURES AND APPENDICES}

Table 1: Distribution of sample firms by industry and region of origin

\begin{tabular}{lccc}
\hline \multicolumn{1}{c}{ Industry } & Europe & Japan & United States \\
\hline Engineering \& General machinery & 14 & 11 & 11 \\
Pharmaceuticals \& Biotech & 12 & 12 & 14 \\
Chemicals & 12 & 11 & 11 \\
IT hardware & 13 & 12 & 17 \\
Electronics \& Electrical machinery & 12 & 15 & 7 \\
Total & $\mathbf{6 3}$ & $\mathbf{6 1}$ & $\mathbf{6 0}$ \\
\hline
\end{tabular}

Table 2: Descriptive statistics

\begin{tabular}{llll}
\hline Variable & Description & Mean & Std. Dev \\
\hline PATENT & Number of patent applications & 125.15 & 253.07 \\
RD & R\&D expenditures & 674.54 & 1070.14 \\
SIZE & Size of patent stock & 547.86 & 1012.03 \\
DIV & Technological diversification & 4.56 & 2.53 \\
COH & Knowledge coherence & 1.33 & 0.95 \\
\hline
\end{tabular}

Table 3: Correlation Matrix

\begin{tabular}{llllllll}
\hline & PAT & RD & PORTFOLIO & DIV & DIV $^{2}$ & COH & DIV $^{*} \mathrm{COH}$ \\
\hline PAT & 1 & & & & & & \\
RD & $0.722^{*}$ & 1 & & & & & \\
PORTFOLIO & $0.926^{*}$ & $0.754^{*}$ & 1 & & & & \\
DIV & $0.17^{*}$ & $0.103^{*}$ & $0.192^{*}$ & 1 & & & \\
DIV $^{2}$ & $0.131^{*}$ & 0.087 & $0.146^{*}$ & $0.963^{*}$ & 1 & & \\
COH & $-0.138^{*}$ & 0.008 & $-0.14^{*}$ & $-0.338^{*}$ & $-0.297^{*}$ & 1 & \\
DIV $^{*} \mathrm{COH}$ & -0.018 & 0.056 & -0.002 & $0.451^{*}$ & $0.430^{*}$ & $0.620^{*}$ & 1 \\
\hline
\end{tabular}

Note: Significance of correlations is indicated by * (0.01) 
Table 4: Results of Negative Binomial Fixed Effects Panel Data Analysis of Firm Technological Performance (PATENT)

\begin{tabular}{|c|c|c|c|}
\hline & Model 1 & Model 2 & Model 3 \\
\hline \multirow[t]{2}{*}{ PORTFOLIO } & $.1312^{* * *}$ & $.1193^{* \star *}$ & $.1344^{* * *}$ \\
\hline & $(.0211)$ & (.0189) & (.0198) \\
\hline \multirow[t]{2}{*}{$R \& D$} & $.0934^{\star \star *}$ & $.1021^{\star \star \star}$ & $.0786^{\star \star}$ \\
\hline & $(.0320)$ & $(.0310)$ & (.0323) \\
\hline \multirow{2}{*}{ DIV } & & $.2652^{\star \star *}$ & $.1593^{\star * \star}$ \\
\hline & & $(.0368)$ & $(.0507)$ \\
\hline \multirow[t]{2}{*}{ DIV $^{2}$} & & $-.0137^{* * *}$ & $-.0100^{\star * *}$ \\
\hline & & $(.0029)$ & $(.0030)$ \\
\hline \multirow[t]{2}{*}{$\mathrm{COH}$} & & & -.04725 \\
\hline & & & $(.0824)$ \\
\hline \multirow[t]{2}{*}{$\mathrm{DIV}^{*} \mathrm{COH}$} & & & $.0740^{\star * *}$ \\
\hline & & & $(.0264)$ \\
\hline \multirow[t]{2}{*}{ y1996 } & .1550 *** & $.1301^{* *}$ & $.1711^{\star \star *}$ \\
\hline & $(.0579)$ & $(.0555)$ & $(.0561)$ \\
\hline \multirow[t]{2}{*}{ y1997 } & $.2134^{\star \star \star}$ & $.1969^{\star \star \star}$ & $.2325^{\star \star \star}$ \\
\hline & (.0533) & $(.0510)$ & $(.0513)$ \\
\hline \multirow{2}{*}{ y1998 } & $.3027^{* * *}$ & $.2918^{* * *}$ & $.3267^{* * *}$ \\
\hline & $(.0520)$ & $(.0495)$ & $(.0497)$ \\
\hline \multirow[t]{2}{*}{ y1999 } & $.3770^{* * *}$ & $.3709^{* * *}$ & $.4045^{\star * *}$ \\
\hline & $(.0507)$ & $(.0483)$ & $(.0483)$ \\
\hline \multirow[t]{2}{*}{ y2000 } & $.4557^{\star \star *}$ & $.4473^{* \star *}$ & $.4746^{\star * *}$ \\
\hline & $(.0496)$ & $(.0474)$ & $(.0474)$ \\
\hline \multirow[t]{2}{*}{ y2001 } & $.5045^{\star \star \star}$ & $.4973^{\star * \star}$ & $.5177^{\star \star *}$ \\
\hline & (.0478) & $(.0457)$ & (.0458) \\
\hline \multirow[t]{2}{*}{ y2002 } & $.5622^{\star \star \star}$ & $.5619^{* \star *}$ & $.5866^{\star \star *}$ \\
\hline & (.0462) & $(.0441)$ & (.0443) \\
\hline \multirow[t]{2}{*}{ y2003 } & $.47685^{\star \star \star}$ & $.4708^{\star \star \star}$ & $.4913^{\star \star *}$ \\
\hline & $(.0465)$ & $(.0446)$ & $(.0446)$ \\
\hline \multirow[t]{2}{*}{ _cons } & $1.3012^{\star \star \star}$ & $.5096^{\star \star *}$ & $.6006^{\star * *}$ \\
\hline & $(.0647)$ & $(.1179)$ & $(.1725)$ \\
\hline $\mathrm{N}$ & 1514 & 1510 & 1496 \\
\hline Number of Groups & 184 & 184 & 184 \\
\hline ॥ & -5683.998 & -5634.725 & -5573.248 \\
\hline chi2 & 376.558 & 500.8676 & 478.41 \\
\hline
\end{tabular}


Figure 1: Predicted Values of Patent Application (PATENT) as a function of Technological Diversification (DIV) and Technological coherence (COH)

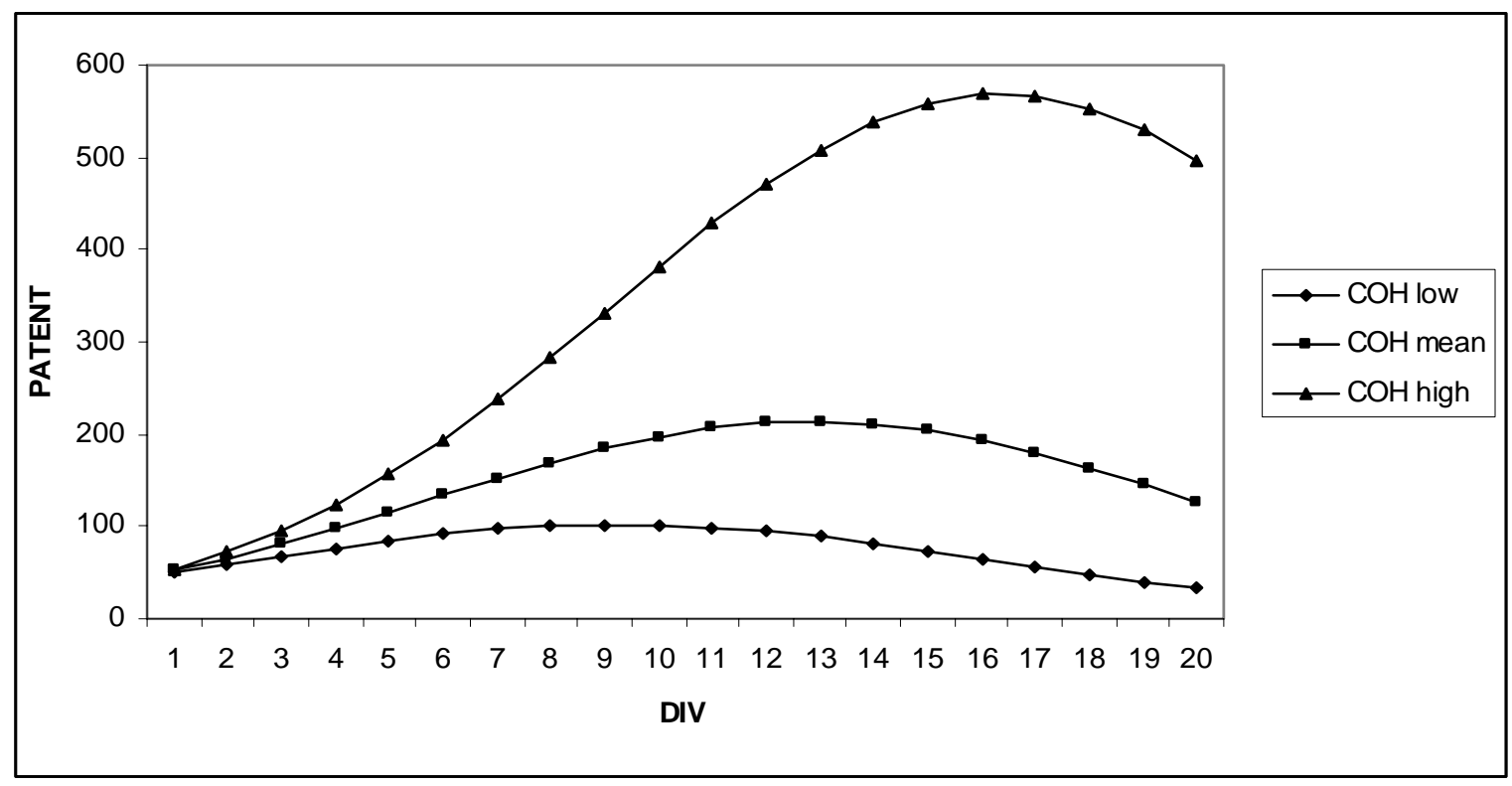




\section{Appendix 1: Technology classification table}

1. Electrical machinery

2. Audio-visual technology

3. Telecommunications

4. Information technology

5. Semiconductors

6. Optics

7. Analysis, measurement and control technology

8. Medical technology

9. Nuclear engineering

10. Organic fine chemistry

11. Macromolecular chemistry, polymers

12. Pharmaceuticals, cosmetics

13. Biotechnology

14. Agriculture, food chemistry

15. Chemical and petrol industry, basic materials

16. Chemical engineering

17. Surface technology, coating

18. Materials, metallurgy

19. Materials processing, textiles, paper

20. Handling, printing

21. Agricultural and food processing machinery

22. Environmental technology

23. Machine tools

24. Engines, pumps, turbines

25. Thermal processes and apparatus

26. Mechanical elements

27. Transport

28. Space technology, weapons

29. Consumer goods and equipment

30. Civil engineering, building, mining 


\section{Appendix 2: Technology Relatedness Matrix}

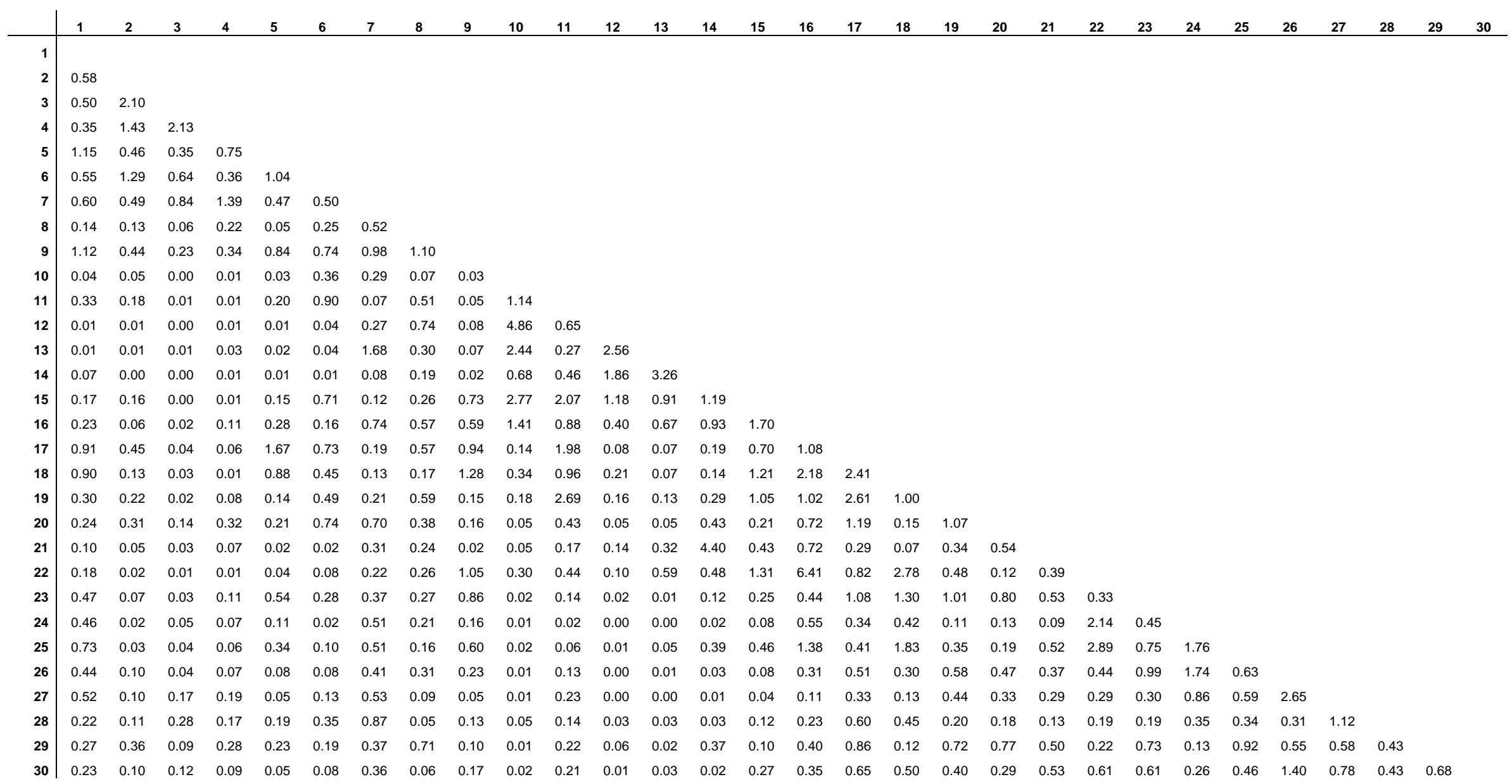




\section{ENDNOTES}

${ }^{1}$ An exception is Nesta and Saviotti (2005) who examine technological diversification and coherence of patent portfolios for a small sample of US bio-pharmaceutical firms. They use a coherence measure due to Breschi, Lissoni and Malerba (2003) and find that coherence has a positive impact on a firm's number of biotech patent applications.

${ }^{2}$ Prencipe (2004) provides evidence for the absorptive capacity argument. For three leading firms in the aircraft engine industry, he noted that their internal technology portfolio remained very broad over time, despite an increase in the outsourcing of the development of components to suppliers.

${ }^{3}$ Suzuki \& Kodama (2004) found empirical proof of such intra-firm cross-fertilization dynamics when analyzing the inventive activities of two large Japanese firms, Canon and Takeda. Canon benefited from the knowledge of camera technologies to develop the technological trajectories of both copiers and semiconductor manufacturing equipment, while knowledge in the field of 'microbes and fermentation' enabled Takeda to deepen competencies in 'organic chemistry'.

${ }^{4}$ See, for instance, the development of a first affordable computerized numerical controller for industrial machine tools by Fanuc as documented by Kodama (1992).

${ }^{5}$ These studies examined patent application data of 31 US bio-pharmaceutical firms, and 544 EU firms (from different sectors), respectively.

${ }^{6}$ For the distinction between exploration and exploitation we refer to March (1991).

${ }^{7}$ We selected industries with the highest patent propensities as reported by Arundel and Kabla (1998): Pharmaceuticals (74\%), Chemicals (57\%), Machinery (54\%), Precision instruments (53\%), Electrical equipment $(43 \%)$ and IT Equipment $(36.5 \%)$.

${ }^{8}$ For citations to patents granted by patent authorities other than EPO and USPTO (about 40 percent of citations), no technology class information was available on a systematic basis. We have worked thus exclusively with EPO and USPTO cited patents found in EPO patent grants.

${ }^{9}$ We make no specific assumption about the form of the distribution of technology classes across cited patents

${ }^{10}$ Pakes and Griliches (1987) show that the relationship between R\&D expenditures and patents is especially strong at the cross-sectional level (R-squares of 0.9), while the same relationship is also significant (but weaker) in the within-firms time-series dimension (R-squares of 0.3 )

${ }^{11}$ We executed a Hausman test which compares random effects and fixed effects estimations of the model. This test rejected the appropriateness of using random effects estimation.

${ }^{12}$ Conservative 2-tailed tests are being used throughout.

${ }^{13}$ We note that parts of the graphs fall out of our sample range: the maximum sample values for DIV are 15,8 and 5.5 for low, mean and high coherent firms, respectively. In addition the predictions are conditional on taking all other covariates in the sample mean. 